\title{
Gênese Instrumental do GeoGebra na Formação de Professores
}

\author{
Instrumental Genesis of GeoGebra in Teacher Education
}

\author{
Márcia Rodrigues Notare ${ }^{1}$ \\ Marcus Vinicius de Azevedo Basso ${ }^{2}$
}

\begin{abstract}
Resumo
Este artigo apresenta a análise do processo de gênese instrumental pessoal a partir de atividades de geometria dinâmica desenvolvidas no Curso de Especialização Matemática - Mídias Digitais - Didática do Programa de Pós-Graduação em Ensino de Matemática da UFRGS, na modalidade à distância para professores do Ensino Básico. O artigo também apresenta análise de indícios de gênese instrumental profissional a partir de implementação de situações de aprendizagem utilizando o software GeoGebra. As análises encontram ancoragem na abordagem instrumental de Rabardel (1995) e fazem parte de pesquisa desenvolvida em cooperação com o Laboratoire de Didactique Andre Revuz da Université Denis Diderot - Paris 7. Identificouse, mediante estudo de caso, avanços no processo de gênese instrumental pessoal do GeoGebra. Da mesma forma, identificou-se indícios do processo de gênese instrumental profissional, na qual o professor-cursista propôs o uso do GeoGebra como um instrumento didático.
\end{abstract}

Palavras-chave: gênese instrumental; geometria dinâmica; formação de professores; educação matemática

\begin{abstract}
This article presents the analysis of personal instrumental genesis process from dynamic geometry activities in the Specialization Course Mathematics - Digital Mídia and Didatics of the Graduate Program in Mathematics Teaching the UFRGS, in distance learning for basic education teachers. The article also presents the analysis of professional instrumental genesis evidence from proposal and implementation of learning situations using GeoGebra. Analyses are anchoring the Rabardel's instrumental approach (1995) and are part of research carried in cooperation with the Laboratoire de Didactique Andre Revuz of the Université Denis Diderot - Paris 7. Search, through case study, identify advances in the process of personal instrumental genesis of GeoGebra, it is possible to observe that the teacher started a technological appropriation process. Similarly, it identified evidence of professional instrumental genesis process, in which the teacher proposed using GeoGebra as a teaching tool.
\end{abstract}

Keywords: instrumental genesis, dynamic geometry, teacher training, mathematics education

\section{Cenário de Investigação}

Em 2014, o Programa de Pós-Graduação em Ensino de Matemática (PPGEMAT) do Instituto de Matemática e Estatística da Universidade Federal do Rio Grande do Sul completou 10 anos de existência. Durante esse período, os trabalhos desenvolvidos nesse Programa estiveram relacionados à reflexão, experimentação e inovação em Educação

\footnotetext{
${ }^{1}$ Doutora em Informática na Educação pela Universidade Federal do Rio Grande do Sul (UFRGS). Professora do Instituto de Matemática da UFRGS e do Programa de Pós-Graduação em Ensino de Matemática da UFRGS. Porto Alegre, RS, Brasil. E-mail: marcia.notare@ufrgs.br.

${ }^{2}$ Doutor em Informática na Educação pela Universidade Federal do Rio Grande do Sul (UFRGS). Professor do Instituto de Matemática, do Programa de Pós-Graduação em Ensino de Matemática, do Programa de PósGraduação em Informática na Educação da UFRGS. Porto Alegre, RS, Brasil. E-mail: mbasso@ufrgs.br.

Zetetiké, Campinas, SP, v.25, n.2, maio/ago.2017, p.324-344.

ISSN 2176-1744
} 
DOI: http://dx.doi.org/10.20396/zet.v25i2.8647864

Matemática, nas salas de aula da Educação Básica e na formação de professores. Também nesse ano, duas novas frentes de trabalho foram abertas no âmbito do PPGEMAT. A primeira foi a oferta da segunda edição do Curso de Especialização Matemática - Mídias Digitais Didática $^{3}$ : Tripé para Formação do Professor de Matemática, na modalidade a distância e para professores do Ensino Básico em serviço; a segunda foi o estabelecimento de cooperação com o Laboratoire de Didactique Andre Revuz (LDAR), da Université Denis Diderot - Paris 7, no desenvolvimento do Projeto Tecnologia Digital na Formação de Professores de Matemática da Educação Básica, com apoio da Fundação de Amparo à Pesquisa do Rio Grande do Sul (FAPERGS), dentro do Programa de Internacionalização da Pós-Graduação do Estado do Rio Grande do Sul (RS).

A cooperação com o LDAR tem como objetivos centrais: (1) o intercâmbio e a difusão de pesquisas que vêm sendo realizadas na área de formação de professores de matemática para o uso de tecnologia digital na sala de aula, no âmbito do PPGEMAT e do $\mathrm{LDAR}^{4}$; (2) o desenvolvimento de projeto de pesquisa conjunto, a partir da análise do processo de gênese instrumental das tecnologias digitais na segunda edição do Curso de Especialização Matemática - Mídias Digitais - Didática.

O Curso teve como proposta central a articulação das componentes Matemática, Mídias Digitais e Didática, e como principais objetivos a atualização dos conhecimentos dos professores de Matemática e a implementação de práticas-pedagógicas utilizando de forma integrada mídias digitais em salas de aulas de Escolas do Ensino Básico.

$\mathrm{Na}$ pesquisa desenvolvida, estamos analisando como esses professores estão vivenciando os processos de gênese instrumental pessoal e profissional, ou seja, como estão se apropriando de mídias digitais ao longo do Curso e como está ocorrendo o processo desta apropriação nas suas salas de aula de Matemática.

É nesse cenário que apresentamos o presente artigo, o qual trata de uma análise sobre os processos de gênese instrumental, nos níveis pessoal e profissional (Rabardel, 1995; Lagrange, 2013) de um professor-cursista ${ }^{5}$ do Curso. Apresentamos um recorte do conjunto de dados desse professor relativo a atividades de geometria dinâmica com o software GeoGebra $^{6}$ e a proposta de utilização e implementação em sala de aula.

\section{O Processo de Gênese Instrumental}

A abordagem instrumental está baseada na distinção que se estabelece entre artefato e instrumento e no processo de transformação progressiva do artefato em instrumento. Para Rabardel (1995), artefato é o objeto material ou simbólico em si, ou parte de um artefato mais

\footnotetext{
${ }^{3}$ http://www.ufrgs.br/espmat

${ }^{4}$ Pesquisas desenvolvidas por Artigue (2002), Lagrange (2013), Abboud-Blanchard eVandebrouck (2013).

${ }^{5}$ Designado apenas por professor na continuidade do artigo.

${ }^{6}$ http://www.geogebra.org.
}

Zetetiké, Campinas, SP, v.25, n.2, maio/ago.2017, p.324-344. 
DOI: http://dx.doi.org/10.20396/zet.v25i2.8647864

complexo, enquanto que instrumento é definido como uma entidade mista, composta pelo artefato mais os esquemas de utilização. Esta entidade mista nasce da relação entre sujeito e objeto. A utilização de esquemas é progressivamente elaborada a partir do uso do artefato em tarefas particulares e, assim, o instrumento é uma construção de cada indivíduo. A elaboração e evolução do instrumento é um processo longo e complexo, o qual Rabardel (1995) denominou de gênese instrumental.

O processo de gênese instrumental é determinado por meio de dois processos: instrumentalização, que consiste na emergência e evolução dos diferentes componentes do artefato, ou seja, consiste em um progressivo reconhecimento das potencialidades e limitações do artefato por parte do sujeito; e instrumentação, que consiste na emergência e desenvolvimento de esquemas de utilização. Os dois processos (Figura 1) são orientados, respectivamente, do sujeito para o objeto e vice-versa, e constituem partes inseparáveis da gênese instrumental.

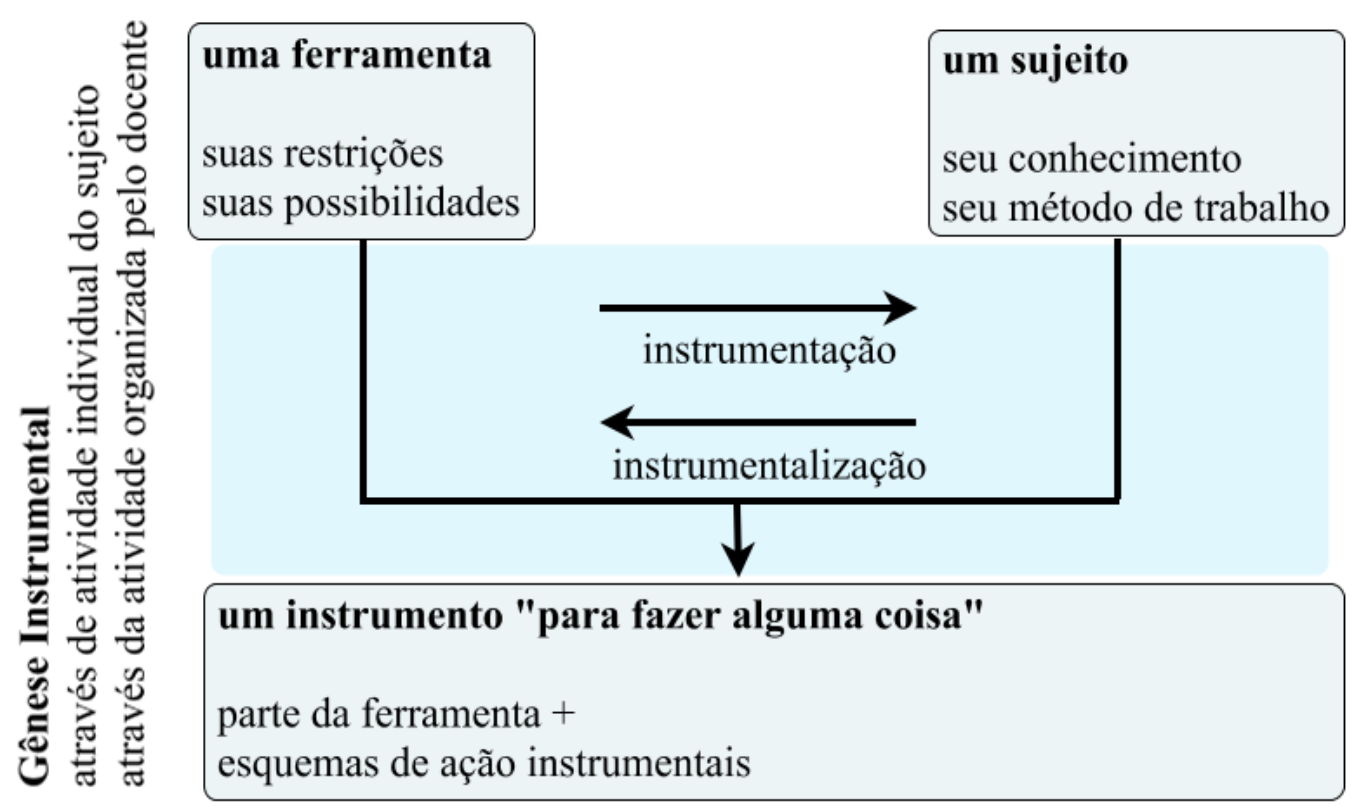

Figura 1 - Exemplo de construção de um dos triângulos da tarefa

Fonte: traduzido de Trouche (2004)

O processo de instrumentação é o processo no qual o artefato imprime uma marca no sujeito, enquanto que o processo de instrumentalização engloba dois estágios: um estágio de descoberta e seleção de funções relevantes do artefato, e um estágio de personalização e de transformação do artefato.

Relacionando este processo com a atividade do professor de Matemática, podemos entender este duplo movimento de instrumentação e instrumentalização da seguinte maneira: o professor se apropria do recurso, explora suas potencialidades técnicas e suas funcionalidades, revelando o movimento de instrumentalização; por outro lado, o artefato e o processo de apropriação influenciam a atividade do professor e, mais amplamente, seu 
DOl: http://dx.doi.org/10.20396/zet.v25i2.8647864

desenvolvimento profissional, revelando o movimento de instrumentação (Bueno-Ravel e Gueudet, 2013).

A elaboração e a utilização de esquemas de uso do artefato estão relacionadas com a experiência do sujeito e, de acordo com esta, estes esquemas vão sendo modificados e/ou integrados aos esquemas já existentes. Para Rabardel (1995), a utilização de uma ferramenta nunca é neutra, pois esta utilização origina-se a partir da mobilização de estruturas cognitivas do sujeito que a está utilizando. Assim, o instrumento é uma construção individual de cada sujeito, pois um mesmo artefato transforma-se em um instrumento diferente para cada sujeito, a partir de esquemas de utilização particulares. Um instrumento comporta, então, parte de um artefato e esquemas de uso associados. Assim, o instrumento não é algo pronto e acabado, pois ele pode ser elaborado e reelaborado pelo sujeito ao longo das atividades realizadas com o artefato (Bittar, 2011).

Quando utilizamos a abordagem instrumental para entender o processo de apropriação de alguma ferramenta pelo professor, entendemos que existem dois processos importantes, os quais precisam ser considerados e analisados: o processo de apropriação tecnológica propriamente dito, ou seja, o processo de gênese instrumental pessoal; e o processo de integração desta ferramenta na sala de aula, ou seja, o processo de gênese instrumental profissional, na qual devem estar presentes reflexões sobre as possibilidades e potencialidades deste recurso para a aprendizagem de Matemática (Haspekian, 2013).

Assim, o processo de gênese instrumental do professor de Matemática é complexo e precisa ser analisado por estas diferentes dimensões: a construção e apropriação para transformar o artefato em uma ferramenta de trabalho matemático (gênese pessoal); e o processo de descoberta das funcionalidades didáticas do artefato, que vão sendo atribuídas a partir do processo de integração do instrumento a suas estratégias de ensino (gênese profissional). Esta dimensão da gênese instrumental se dá, então, pela construção e apropriação de um instrumento didático para a aprendizagem de Matemática, a partir do primeiro instrumento, construído pela gênese pessoal.

Para Haspekian (2013), este fenômeno de dupla gênese do professor interfere na gênese dos alunos, pois as limitações de uso da ferramenta interferem no projeto de ensino, que pode se tornar limitado, sem tirar o devido proveito do potencial didático que a ferramenta pode oferecer. Se a ferramenta ainda está se tornando um instrumento pessoal para o professor, em uma fase em que ele ainda não a explorou e desvendou totalmente, não pode se tornar um instrumento didático para ensinar Matemática. A ferramenta não se torna um instrumento didático de forma imediata; ela vai progressivamente se transformando neste instrumento pelo processo de gênese profissional.

A gênese instrumental profissional coloca em jogo os esquemas relativos à gestão da classe e à aprendizagem dos alunos, enquanto que a gênese instrumental pessoal coloca em jogo os esquemas que não são diretamente relacionados à utilização do instrumento com os alunos e que não necessariamente integra elementos de reflexão didática. Ou seja, a gênese pessoal conduz o professor a focar na técnica e a gênese profissional o conduz a focar no uso do instrumento na sala de aula, tomando consciência sobre o potencial da tecnologia. 
DOI: http://dx.doi.org/10.20396/zet.v25i2.8647864

Bittar (2011) utilizou esta abordagem teórica para estudar os esquemas desenvolvidos por professores de um grupo de estudos engajados na construção de uma nova prática que utilizasse a tecnologia em sala de aula. Foi escolhido o software SuperLogo e as discussões do grupo eram conduzidas de modo a pensar sobre como utilizar o software para favorecer a aprendizagem de Matemática. Segundo Bittar (2011), a abordagem instrumental permite melhor compreender como o professor apreende e incorpora a tecnologia em prática pedagógica.

$\mathrm{Na}$ seção a seguir, vamos analisar o processo de gênese instrumental do software GeoGebra, em suas duas dimensões: pessoal e profissional.

\section{O Curso de Especialização Matemática - Mídias Digitas - Didática}

O Curso de Especialização Matemática - Mídias Digitais - Didática foi oferecido pelo PPGEMAT/UFRGS em parceria com a UAB, na modalidade a distância, em sua segunda edição, no período de outubro de 2013 a agosto de 2015.

Nesta edição do Curso foram oferecidas 180 vagas para seis polos do RS tendo como objetivo central articular as componentes Matemática, Mídias Digitais e Didática para dar formação aos professores de Matemática da Educação Básica, com foco na integração de mídias digitais na sala de aula.

$\mathrm{Na}$ proposta curricular do Curso, cada disciplina aborda diferentes conceitos matemáticos e discute o potencial das tecnologias digitais no processo de aprendizagem. Desta forma, os professores aprendem a utilizar diferentes softwares, como GeoGebra, GrafEq e Winplot, e utilizando estes softwares em suas aulas, refletem sobre suas práticas de ensino. O Curso ainda possui o Trabalho de Conclusão de Curso (TCC), no qual os professores devem elaborar, aplicar e refletir sobre uma experiência de ensino realizada em sala de aula da Educação Básica utilizando mídias digitais.

Há um conjunto de quatro pares de disciplinas, compostas por uma de Matemática e Tecnologia acompanhada de uma de Teoria e Prática Pedagógica. Nestas disciplinas foi proposto que os professores elaborassem um plano de ensino utilizando o recurso digital estudado para abordar algum conteúdo de Matemática escolar.

Neste artigo enfocaremos atividades desenvolvidas nas disciplinas Mídias Digitais na Educação Matemática I (MD-I) e Teoria e Prática Pedagógica I (TP-I) e um TCC, para analisar como o professor foi se apropriando do software GeoGebra e como refletiu sobre o uso deste recurso na sua aula, tornando-o um instrumento didático para a aprendizagem de Matemática. A seção a seguir descreve este par de disciplinas.

\section{Mídias Digitais na Educação Matemática I}

A disciplina MD-I, na qual foram tratados conceitos de geometria euclidiana plana, funções e gráficos, teve como objetivo discutir possibilidades de uso do GeoGebra para o ensino e aprendizagem da Matemática na escola. 
DOI: http://dx.doi.org/10.20396/zet.v25i2.8647864

Para iniciar o trabalho com o GeoGebra foi explorada a ideia de figuras dinâmicas e suas implicações na sala de aula. A disciplina, organizada em sete módulos ao longo de dez semanas, pode ser visitada no website do Curso $^{7}$. Em cada módulo foi proposta uma discussão sobre possibilidades de utilização de recursos digitais em sala de aula e, ao final da disciplina, foi solicitada a elaboração de um plano de ensino que explorasse o GeoGebra para a aprendizagem de um tópico de Matemática.

Como exemplo de atividade desenvolvida, selecionamos a tarefa proposta no Módulo II (Figura 2). Nesta tarefa, a partir da manipulação dos vértices dos triângulos, deveriam ser identificadas suas propriedades e criadas categorias para classificá-los. Para cada triângulo, deveriam ser descritas suas propriedades, realizar a construção no GeoGebra e apresentar os passos da construção. Ainda, considerando que os passos da construção são fatos declarados, deveriam ser apresentadas propriedades resultantes da construção realizada, ou seja, os fatos implícitos na construção.

Por exemplo, o triângulo nomeado de pol4 é um triângulo construído a partir de dois pontos livres, determinando um dos lados do triângulo, e o terceiro vértice é construído sobre uma circunferência cujo diâmetro coincide com este lado. Portanto, o triângulo pol4 é triângulo retângulo. São fatos declarados os dois pontos livres e o ponto sobre a circunferência de diâmetro igual ao lado livre; é fato implícito o ângulo reto formado a partir do terceiro vértice construído.

A partir do relatório dos professores e da classificação atribuída a cada triângulo, foi possível analisar se eles identificaram as propriedades implícitas e, a partir das construções realizadas no GeoGebra, analisar se estavam se apropriando do recurso tecnológico e compreendendo os princípios da geometria dinâmica.

\footnotetext{
${ }^{7}$ http://www.ufrgs.br/espmat/disciplinas/midias_digitais_I/
} 
Tarefa II: (para entregar no moodle) observe as peculiaridades ou características que cada triângulo apresenta. Se necessário, utilize alguns recursos do GeoGebra que estão disponiveis na barra de ferramentas para testar suas conjecturas e analisar possiveis propriedades. A partir destas propriedades que você observa, crie categorias, e organize os triângulos de modo a agrupar aqueles que estão na mesma categoria.

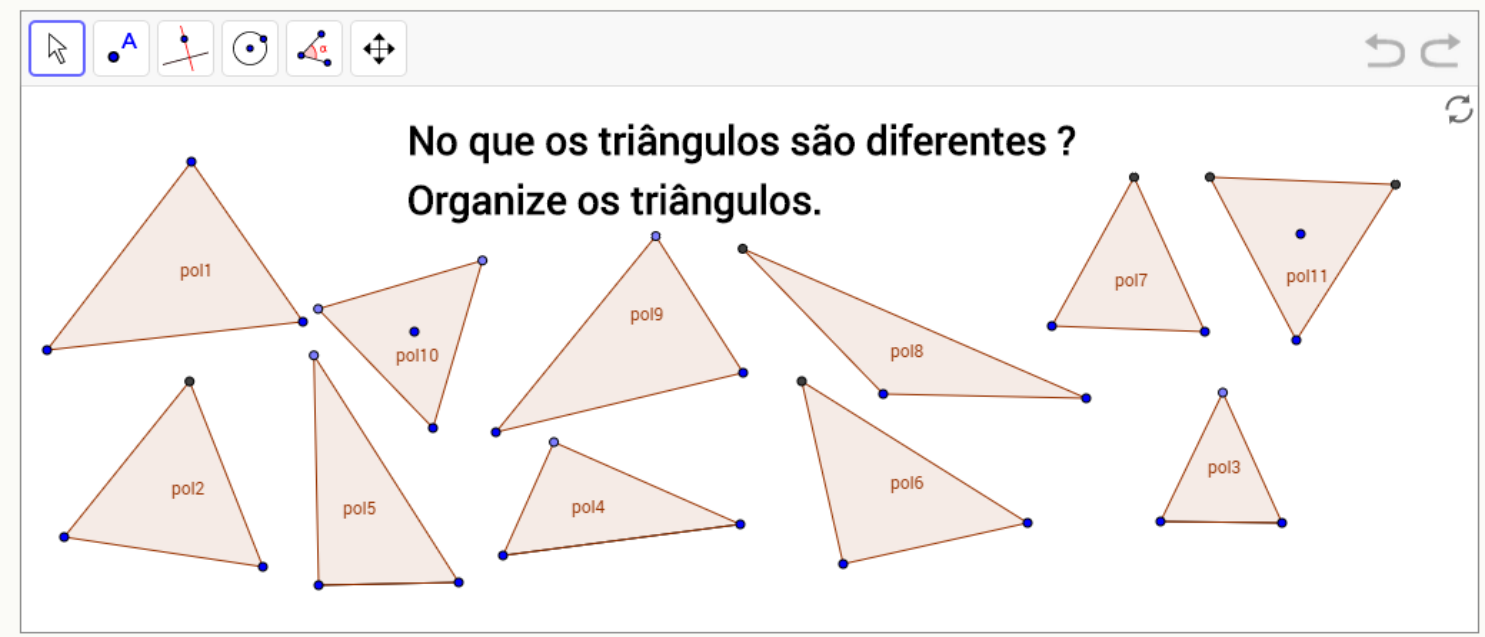

Para cada um dos triângulos apresentados:

a) registre as características ou propriedades geométricas observadas;

b) crie categorias (apresentando uma descrição de cada categoria), e classifique cada triângulo conforme as categorias criadas.

c) apresente os passos da construção (fatos declarados) e as outras propriedades observadas (fatos implícitos),

Para realizar esta tarefa, envie dois arquivos no moodle:

- arquivo de texto (.doc ou semelhante): contendo as respostas para cada uma das perguntas acima, referentes a cada uma das figuras apresentadas No mesmo arquivo, encaminhe o relatório da atividade (veja instruções para o relatório).

- arquivo do GeoGebra (.ggb): com as construções das figuras, de modo que as figuras se comportem da mesma forma do apresentado.

Figura 2 - Tarefa 2 da disciplina Mídias Digitais I

Fonte: http://www.ufrgs.br/espmat

Outra tarefa proposta encontra-se na Figura 3. Aqui, a ideia era a construção de quadriláteros a partir do segmento diagonal e, para isso, estava implícito o conhecimento sobre as propriedades das diagonais destes polígonos. Novamente nos apoiamos sobre as construções realizadas no GeoGebra e sobre o relatório da atividade para buscar indícios do processo de apropriação da ferramenta pelo professor.

Tarefa III: (para entregar no moodle) a partir da diagonal, represente o paralelogramo, retângulo e losango no GeoGebra, observando:

- a representação deve ser geral, ou seja, não deve se restringir a casos particulares;

- a representação deve partir da diagonal, ou seja, é o primeiro segmento a ser representado;

- que ao movimentar os vértices, a representação mantenha as características desejadas;

Em seguida, realize o relatório da atividade, indicando os fatos declarados e fatos implícitos, bem como as propriedades relacionadas às diagonais.

Para realizar esta tarefa, envie dois arquivos no moodle

- arquivo de texto (.doc ou semelhante): contendo o relatório da atividade conforme modelo disponível no moodle.

- arquivo do GeoGebra (.ggb): com as construções dos quadriláteros solicitados.

Figura 3 - Tarefa 3 da disciplina Mídias Digitais I

Fonte: http://www.ufrgs.br/espmat 
Teoria e Prática Pedagógica I

DOl: http://dx.doi.org/10.20396/zet.v25i2.8647864

A disciplina TP-I, integrada com MD-I, tinha como objetivo pensar o espaço da sala de aula como um campo para a aprendizagem da Matemática utilizando o GeoGebra. Assim, havia uma expectativa quanto à incorporação de conhecimentos dos campos da Matemática, do recurso digital e da Didática nos planos de ensino elaborados pelos professores.

Para isso, os professores participantes do Curso foram orientados a elaborar um plano de aula contemplando as seguintes orientações: 1) o tema abordado deveria envolver os tópicos estudados na disciplina MD-I, ou apresentar relação direta com os conteúdos geometria e figuras, geometria e álgebra, geometria e funções; 2) justificar a escolha do tema; 3) envolver a utilização do GeoGebra, explorando o potencial de utilização para a aprendizagem matemática; 4) propor uma sequência de atividades ou questões a serem apresentadas aos alunos; 5) descrever o papel do professor durante a realização desta aula destacando "Que tipo de intervenções são feitas?", "Como as atividade são conduzidas?", "Como os estudantes são questionados?"; "Frente a situações não previstas, como, por exemplo, perguntas inusitadas, que tipo de atitude didática pode ser adotada?".

Em uma segunda etapa, os planos apresentados foram discutidos em fóruns virtuais em grupos formados por três professores. Essas discussões culminavam com a escolha e aperfeiçoamento didático, matemático e de uso de tecnologias em sala de aula de um desses planos para sua aplicação nas Escolas dos professores. Como sugestão, foi proposto que um dos participantes conduzisse a atividade na função de professor e os demais integrantes do grupo fizessem a observação e coleta de dados, tal como registro escrito, gravação da atividade ou de parte das intervenções do professor e falas dos estudantes.

Neste artigo, analisamos o desenvolvimento de um professor sob dois aspectos: (1) o processo de apropriação do GeoGebra e (2) a utilização do GeoGebra como instrumento didático para a aprendizagem de Matemática.

A abordagem instrumental de Rabardel (1995) será utilizada nesta análise, ou seja, entendemos que o processo de apropriação do GeoGebra consiste em um processo de gênese instrumental pessoal e a utilização de GeoGebra como instrumento didático em um processo de gênese instrumental profissional.

\section{Análise dos Processos de Gênese Pessoal e Profissional}

Para realizar esta análise, foi feita inicialmente a seleção de trinta professores, matriculados em dois dos seis polos nos quais o Curso foi oferecido. Uma análise geral das produções destes professores foi feita e foram selecionados oito participantes para dar continuidade à pesquisa. Em seguida, uma análise minuciosa da produção desses oito foi realizada. Os oito selecionados possuem perfil representativo do grupo de professores em termos de frequência e desempenho na realização das atividades. No critério frequência, consideramos professores que realizaram todas as atividades propostas e no critério desempenho procuramos contemplar uma amostra de estratégias variadas na apresentação das soluções para as atividades envolvendo o GeoGebra. Trazemos neste artigo a análise do 
DOI: http://dx.doi.org/10.20396/zet.v25i2.8647864

processo de gênese instrumental de um professor, denominado por $\mathrm{A}$, a partir da análise de tarefas entregues na disciplina MD-I e do TCC, no qual foi contemplada a realização de prática de ensino com estudantes de Escola Básica. Esse sujeito foi selecionado a partir de dois critérios: (1) apresentação de soluções matematicamente corretas para atividades da disciplina MD-I e (2) não ter conhecimento prévio sobre o software GeoGebra.

De acordo com Ponte (2006, p.2), "Um estudo de caso visa conhecer uma entidade bem definida como uma pessoa, uma instituição, um curso, uma disciplina, um sistema educativo, uma política ou qualquer outra unidade social.". Particularmente, "Na Educação Matemática, os estudos de caso têm sido usados para investigar questões de aprendizagem dos alunos bem como do conhecimento e das práticas profissionais de professores, programas de formação inicial e contínua de professores (...)" (Ponte, 2006, p. 3). Assim, a seleção deste professor atende ao interesse desta pesquisa na medida em que análises sobre a gênese instrumental de um sujeito que desconhece o software GeoGebra e incorpora esse recurso digital em uma prática na Escola, representa um "caso exemplar" (Ponte, 2006) bem sucedido do ponto de vista dos objetivos do Curso.

Para analisar o processo de gênese pessoal, consideramos os seguintes aspectos: (1) o professor estabelece um plano de ação global para as construções realizadas no GeoGebra, ou as construções são realizadas sem um plano global, a partir de tentativas e erros; (2) as construções realizadas são gerais ou representam um caso particular e, neste caso, o professor toma consciência da particularidade de sua construção; (3) qual o nível de conhecimento matemático que se pode identificar nas construções apresentadas.

$\mathrm{Na}$ análise do processo de gênese profissional consideramos os seguintes aspectos: (1) o professor tem consciência sobre o potencial da tecnologia para a aprendizagem de Matemática. No caso específico da geometria dinâmica, procuramos identificar se o plano de ensino explorou adequadamente o potencial dinâmico do GeoGebra; (2) os papéis do aluno e do professor no planejamento; (3) o tipo de atividade proposta, ou seja, se foi pensada uma atividade guiada, ou uma atividade com caráter exploratório; (4) a concepção da atividade matemática, observando se as atividades propostas têm natureza empírica ou dedutiva, se envolvem raciocínios generalizadores.

\section{Gênese Pessoal}

Nessa subseção serão analisadas as atividades descritas na seção 3 do sujeito A.

\section{Análise da Tarefa II - Triângulos Dinâmicos}

A tarefa II consistia em observar, a partir da manipulação dos vértices de onze triângulos distintos, as características e propriedades de cada triângulo. A partir das propriedades observadas, os professores deveriam criar categorias e organizar os triângulos de modo a agrupar aqueles que estavam na mesma categoria.

Desta forma, é por meio do dinamismo das figuras que as propriedades de cada triângulo se revelam, com maior ou menor evidência. Também por meio desta exploração são identificadas as indicações para os procedimentos de construção. 
DOl: http://dx.doi.org/10.20396/zet.v25i2.8647864

Sobre os triângulos propostos pela atividade, o triângulo pol1 é um triângulo com três vértices livres e, portanto, é um triângulo qualquer. Os triângulos pol2, pol6, pol7 e pol8 são triângulos com dois vértices livres e o terceiro vértice é um ponto fixo. Este tipo de dinamismo indica que os triângulos têm particularidades e o movimento aplicado em cada um gera uma família de triângulos semelhantes: movimentando pol2, é possível intuir que o triângulo é equilátero e sua construção pode ser evidente, ou seja, suas propriedades podem ser identificadas a partir da movimentação dos pontos livres; movimentando pol6, pode-se intuir que o triângulo é retângulo e isósceles e sua construção também pode ser evidente; movimentando pol7, não é trivial determinar as propriedades que o caracterizam como um triângulo equilátero ou isósceles e, portanto, sua construção não é evidente; movimentando pol8, pode-se intuir que o triângulo é isósceles, mas a construção também pode não ser evidente.

Prosseguindo na análise, o triângulo pol11 possui dois pontos móveis, sendo um deles vértice do triângulo e o outro um ponto no seu interior; a partir da movimentação, pode-se intuir que o triângulo é equilátero, mas sua construção também não é evidente e esta pode ser a construção mais complexa da atividade. Quatro triângulos (pol3, pol4, pol5 e pol9) têm dois vértices livres e o terceiro vértice com movimento restrito; isto significa que cada triângulo tem uma particularidade e dois representantes de um mesmo triângulo não estão em relação de semelhança. Famílias de triângulos isósceles são dadas por pol3 e pol9; em pol3, o terceiro vértice é construído sobre a mediatriz do segmento "base" e em pol9 o terceiro vértice é construído sobre o círculo definido por um dos lados do triângulo que não é a base. Famílias de triângulos retângulos são dadas por pol 4 e pol5: em pol4 o vértice que garante o ângulo reto move-se sobre um círculo, este com diâmetro definido pelo primeiro lado do triângulo, e aqui não é evidente visualizar o ângulo reto, pois este fato decorre de teorema do ângulo inscrito na circunferência; em pol5 o ponto com movimento restrito está na reta perpendicular ao primeiro cateto já construído e, neste caso, o dinamismo mostra de forma evidente o ângulo reto do triângulo. O triângulo pol10 possui quatro pontos móveis (os três vértices e mais um quarto ponto). No dinamismo, pode ser observado que o triângulo muda de tamanho a partir de movimento de um dos vértices e do quarto ponto; os outros dois vértices têm movimento circular. Não é simples o entendimento geométrico da situação a partir do dinamismo. O quarto ponto móvel tem a propriedade de ser o circuncentro de uma família particular de triângulos.

$\mathrm{Na}$ análise geral das construções apresentadas pelo professor A, percebe-se que as construções estão corretas, com descrição adequada das propriedades observadas para cada triângulo. Os fatos declarados e os fatos implícitos foram identificados corretamente e a organização de categorias de triângulos também é adequada. Porém, é importante realçar que A utiliza o recurso de medida para se certificar sobre as propriedades que foram identificadas, medindo lados e ângulos, como podemos observar na Figura 4. 
DOI: http://dx.doi.org/10.20396/zet.v25i2.8647864
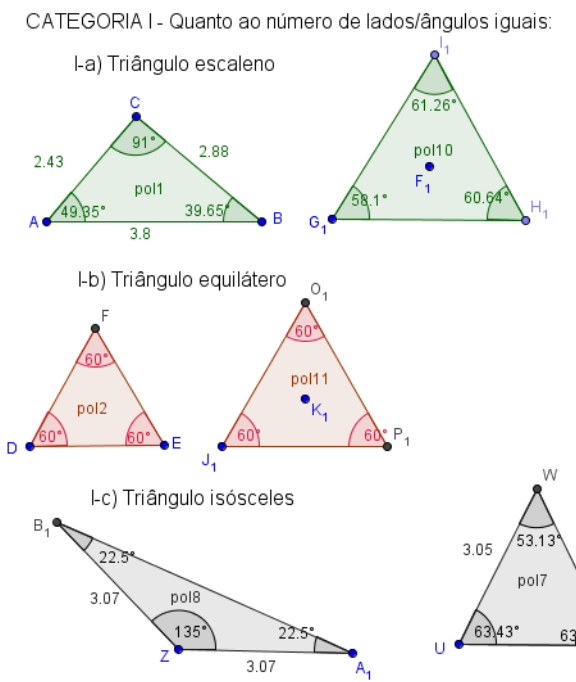

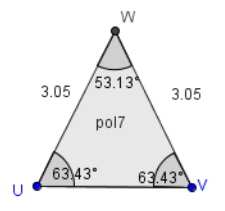

Figura 4 - Atividade do professor-aluno A

Fonte: http://www.ufrgs.br/espmat
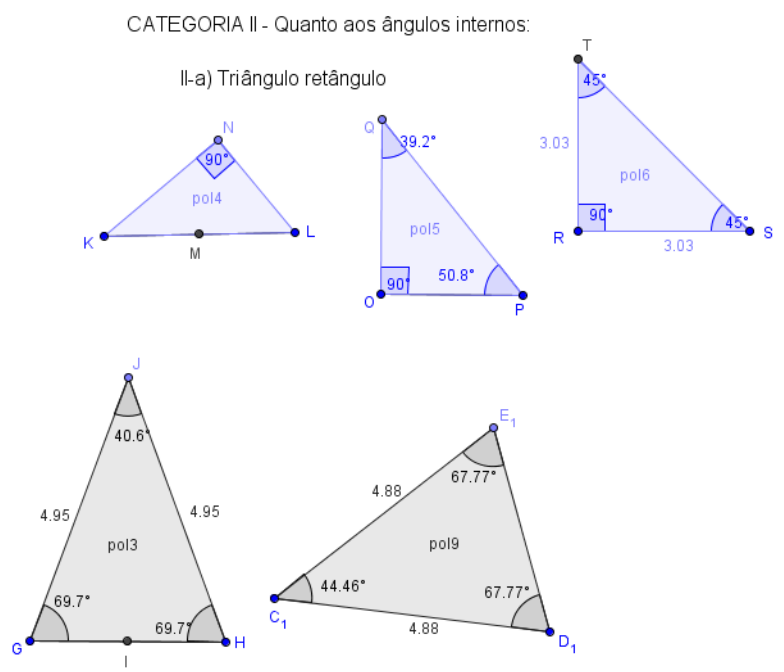

Para todos os triângulos, A identifica os pontos livres e os pontos com restrição de movimento. Para os triângulos com um vértice sem movimento, em dois deles A traz informação obtida a partir do dinamismo e apresenta o procedimento de construção. Para o triângulo pol2, A descreve o procedimento de construção: "todos os ângulos são iguais, com medida $60^{\circ}$; os lados aparentemente tem a mesma medida, independente do movimento dos vértices; um vértice é o ponto de interseção entre as duas circunferências que tem como centro os outros dois vértices, e seu movimento é consequência do movimento destes vértices.".

Para o triângulo pol6, A identifica o ângulo reto do triângulo e também identifica que os ângulos têm medida constante, mas não identifica a particularidade de ser isósceles: " $o s$ ângulos tem medida fixa, sendo um dos ângulos reto; o vértice correspondente ao ângulo reto é centro da circunferência; um vértice é ponto de interseção entre a circunferência e a reta perpendicular que passa pelo centro da circunferência.".

As particularidades dos triângulos pol7 e pol8 não são facilmente identificadas por meio do dinamismo. Para o triângulo pol7, A apresenta uma descrição geral e, neste primeiro momento, nada diz sobre o procedimento de construção: "o vértice preto não é ponto de interseção entre as circunferências com centro nos outros vértices; os ângulos da base são iguais e tem medida fixa.". Para identificar as particularidades de pol8, A usa o recurso de medidas e apresenta os procedimentos de construção: "o triângulo sempre é obtusângulo; o vértice relativo ao ângulo obtuso é o centro da circunferência que passa pelos outros dois vértices; para obter o ângulo de $135^{\circ}$, pode-se traçar a bissetriz de um ângulo reto $\left(90^{\circ}+45^{\circ}\right.$ $=135^{\circ}$ ); dois lados do triângulo são raios da circunferência, logo, o triângulo deve ser isósceles.".

Para o triângulo pol11, A identifica e informa suas propriedades, mas não explicita, neste momento, o procedimento de construção: "todos os ângulos são iguais, com medida 
DOI: http://dx.doi.org/10.20396/zet.v25i2.8647864

$60^{\circ}$; o ponto situado no interior do triângulo é o centro da circunferência circunscrita ao triângulo, ou seja, é o encontro das mediatrizes do triângulo.".

Nos triângulos que possuem dois vértices livres e um terceiro com restrição de movimento, no caso dos triângulos isósceles, A identifica que um vértice se movimenta na mediatriz de um segmento (no caso de pol3) ou percebe que um vértice tem movimento circular (no caso de pol9). Para os triângulos retângulos, A percebe que um dos vértices se movimenta em reta perpendicular a um lado do triângulo ou identifica que um dos vértices se movimenta sobre um círculo. Em relação ao triângulo pol4, também traz informação sobre o procedimento de construção: "o triângulo sempre é retângulo; um lado do triângulo é o diâmetro da circunferência que tem centro em seu ponto médio; um vértice é ponto livre sobre a circunferência, por isso apenas o ângulo reto tem medida fixa, os outros dois ângulos são variáveis, conforme movimento do ponto livre.". Percebe-se aqui a presença de conhecimento matemático, que possibilitou ao professor A reconhecer o triângulo como um triângulo retângulo. Em relação ao triângulo pol5, A apresenta informações sobre a construção: "o triângulo sempre é retângulo; há um ponto livre sobre a reta perpendicular à base do triângulo, logo, apenas o ângulo reto tem medida fixa; a medida dos outros ângulos depende do movimento do ponto livre.".

Para o triângulo pol10, A descreve suas propriedades, mas não explicita o procedimento de construção: "todos os ângulos são diferentes; - o ponto situado no interior do triângulo é o centro da circunferência circunscrita ao triângulo, ou seja, é o encontro das mediatrizes do triângulo; há dois pontos livres sobre a circunferência; o outro vértice também se desloca sobre a circunferência".

Nesta atividade, A apresenta os passos de construção com clareza e com coerência lógica. Em quase todos os casos, é na fase inicial da tarefa, no momento de exploração do movimento dos pontos livres, que A identifica o procedimento de construção. Dependendo do tipo de dinamismo, conforme explicitados na descrição das construções dos triângulos dinâmicos, o procedimento de construção já pode ficar evidente no movimento de pontos. Mas este não é o caso dos triângulos pol7 e pol11. Para construir o triângulo pol11, A afirma ter tido dificuldade. Contudo, apresenta um processo de construção, que pode ser observado na Figura 5.

Tanto na identificação de regularidades, apoiadas na exploração do dinamismo, quanto nas construções apresentadas por A, identifica-se um processo de instrumentalização em andamento, seja pelos procedimentos bem elaborados de construção, seja pelo uso de menus que não foram apresentados pelo professor. O professor A iniciou o Curso revelando que desconhecia o software GeoGebra e iniciando um processo de apropriação deste artefato, explorando suas potencialidades e funcionalidades, evidenciando um estágio de personalização e transformação do GeoGebra. 
DOI: http://dx.doi.org/10.20396/zet.v25i2.8647864

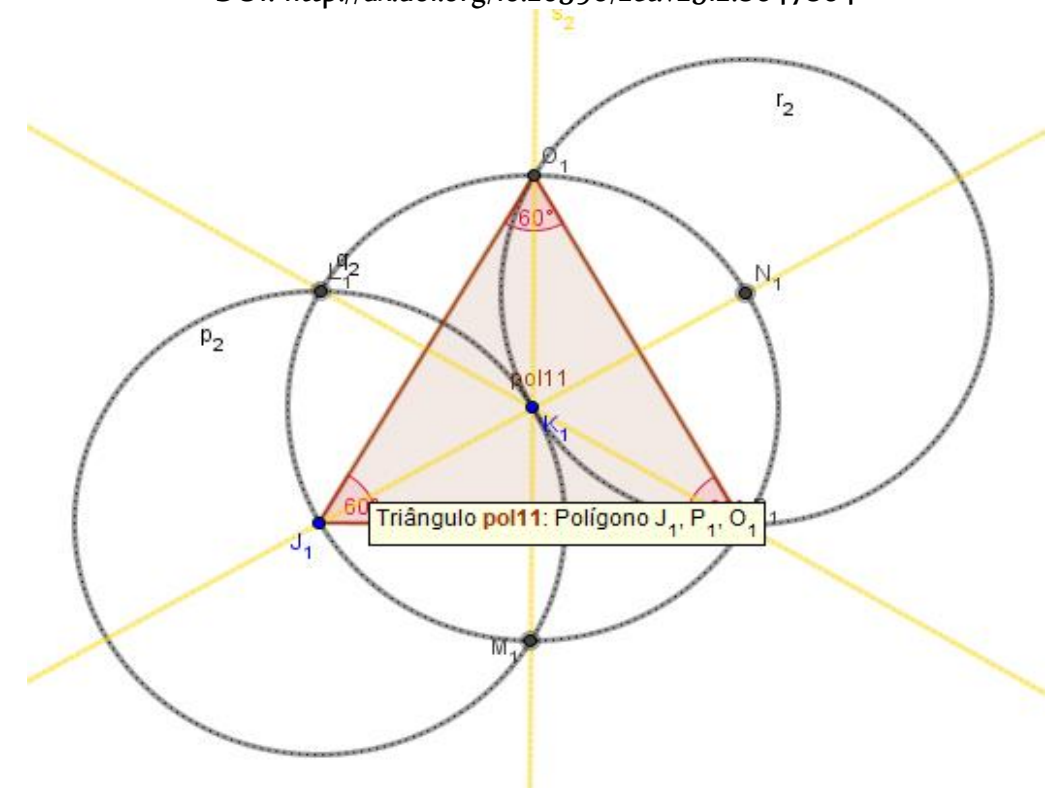

Figura 5 - Construção do triângulo pol11

Fonte: http://www.ufrgs.br/espmat

Quanto às regularidades e propriedades geométricas que podem ser observadas quando se movimenta pontos da figura, o uso do potencial da geometria dinâmica se fez presente de forma consistente. O professor A identifica as propriedades das figuras e os procedimentos de construção em nove dos onze triângulos propostos pela atividade, por meio do dinamismo e da utilização de recursos de medidas. Nos casos dos triângulos pol7 e pol11 isto não acontece, provavelmente pelo fato de que existe uma distância conceitual entre as propriedades que podem ser observadas nestes triângulos via dinamismo e o procedimento de construção a ser feito.

Quanto ao conhecimento matemático, realçamos que A fez uma adequada organização dos triângulos em categorias, identificando triângulos quaisquer, triângulos equiláteros, triângulos isósceles e triângulos retângulos. Ainda, A faz um comentário correto sobre as classificações dos triângulos: "No entanto, vale ressaltar que alguns triângulos poderiam ser classificados quanto a mais de um critério, o que de certa forma dificulta na organização dos mesmos, no sentido de ficar-se indeciso em relação a qual categoria integrar o triângulo que apresenta características das duas categorias estabelecidas.".

Quanto aos fatos implícitos, uma tarefa não trivial de ser realizada, A observa fatos relevantes, bem como fatos irrelevantes. Mas A mostra compreensão da ideia de fatos declarados e fatos implícitos ao dizer que: "Quanto aos fatos declarados e implícitos, citados anteriormente, os "fatos declarados" estão diretamente relacionados com a construção da figura geométrica, ou seja, são as características e propriedades observadas nos passos de construção. Já os "fatos implícitos" estão subentendidos, são aqueles que não foram construídos, no entanto, são consequência da construção, ou seja, complementam os fatos declarados, no sentido de verificar e confirmar a existência de propriedades na figura geométrica através de demonstração". 
DOI: http://dx.doi.org/10.20396/zet.v25i2.8647864

Sobre o uso do dinamismo, A afirma: "Iniciei com a análise e a observação das características das figuras apresentadas na atividade proposta, utilizando alguns dos recursos disponíveis na barra de ferramentas, verificando assim as possíveis propriedades das figuras e seu comportamento através do seu dinamismo.". Temos aqui indícios de que A compreende os princípios da geometria dinâmica e sua importância para a aprendizagem de Matemática. Podemos identificar também que A desenvolveu esquemas de uso do GeoGebra, explorando e utilizando diferentes recursos da barra de ferramentas para realizar as atividades propostas. O GeoGebra está se transformando em uma ferramenta de trabalho matemático.

Análise da tarefa III - construção de quadriláteros a partir das diagonais

A tarefa III consistiu em solicitar que cada professor, a partir da diagonal, representasse o paralelogramo, o retângulo e o losango no GeoGebra, observando que:

- a representação deve ser geral, ou seja, não deve se restringir a casos particulares;

- a representação deve partir da diagonal, ou seja, é o primeiro segmento a ser representado;

- ao movimentar os vértices, a representação deve manter as características desejadas.

Também foi solicitado que, ao realizar o relatório individual da atividade, cada professor indicasse os fatos declarados e os fatos implícitos, bem como as propriedades relacionadas às diagonais.

Destacamos a construção do retângulo a partir de uma de suas diagonais (segmento AB) realizada pelo professor A (Figura 6).

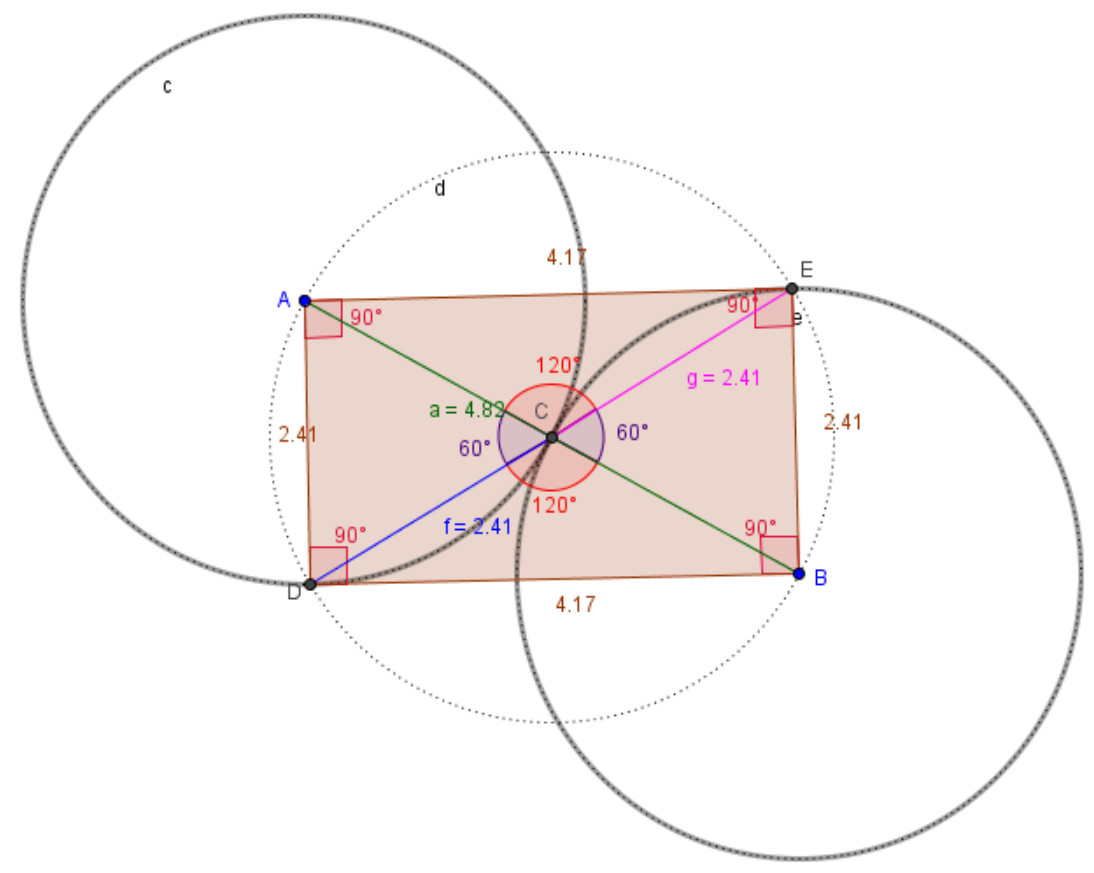

Figura 6 - Construção do retângulo

Fonte: http://www.ufrgs.br/espmat 
DOI: http://dx.doi.org/10.20396/zet.v25i2.8647864

Foi possível observar, via procedimentos identificados no protocolo de construção analisados no arquivo do GeoGebra, que o professor A partiu da diagonal para construir o retângulo, conforme solicitado.

No entanto, embora a construção apresente estabilidade, ou seja, é sempre retângulo, trata-se de um caso particular, pois, tem somente dois vértices opostos livres, contendo em seu interior dois triângulos equiláteros. Aqui, a construção do terceiro vértice livre no círculo, e que garantiria generalidade da construção, não foi feita. Ou seja, temos uma construção estável, mas não geral. Nas palavras de A: "A construção de quadriláteros no software GeoGebra exige alguns cuidados para que as suas propriedades não se modifiquem e a figura não se deforme ao movimentar seus vértices. Sendo assim, ao iniciar a construção destas figuras no GeoGebra, é necessário atentar para as propriedades das diagonais, conforme segue: No retângulo, sabe-se que as diagonais são oblíquas, iguais e se interceptam no ponto médio. Sendo assim, inicia-se a construção pelo segmento AB e marcase o ponto médio $C$. Em seguida, traçam-se as circunferências com centro A passando por $C$, com centro $C$ passando por A e com centro B passando por $C$. Assim, localizam-se os pontos de interseção $D$ e E. Ao analisar a figura, conclui-se que: os segmentos $D E$ e AB são diâmetros da circunferência com centro em C, logo, são iguais; o ponto C também é ponto médio do segmento DE; as diagonais são oblíquas (facilmente constatado ao marcar os ângulos). Sendo assim, ao aplicar movimento aos vértices, verifica-se que estas propriedades não se modificam, ou seja, o retângulo muda de tamanho e posição, mas não se deforma.".

Outro aspecto notável é que, ainda que a construção tenha sido feita a partir das propriedades geométricas, A utiliza medidas, como se pode observar nas construções dos três quadriláteros. Qual a origem dessa necessidade? Da Escola, que enfatiza o trabalho com medidas dando menor destaque para as propriedades geométricas? Das próprias noções construídas a partir de uma geometria não-dinâmica? Dos esquemas de uso particulares elaborados por A no processo de apropriação do GeoGebra e que são marcados pela sua experiência pessoal? Conforme Rabardel (1995), a utilização de um instrumento nunca é neutra, é uma construção individual de cada sujeito e, aqui, percebemos que A faz uso de estratégias próprias, não enfatizadas pelo Curso.

Quanto aos fatos implícitos e fatos declarados, A demonstra discernimento e constrói argumentos que demonstram que a figura retângulo apresenta as propriedades desejadas, como na descrição a seguir (Figura 7). 
DOI: http://dx.doi.org/10.20396/zet.v25i2.8647864

\begin{tabular}{|c|c|c|}
\hline & Fatos declarados & Fatos implícitos \\
\hline Retângulo & $\begin{array}{l}\text { - C é o ponto médio do } \\
\text { segmento } A B \text { (diagonal), } \\
\text { portanto } \overline{A C} \equiv \overline{C B} \\
-\overline{D C} \text { e } \overline{C E} \text { são raios da } \\
\text { circunferência d, portanto } \\
\overline{D C} \equiv \overline{C E}\end{array}$ & $\begin{array}{l}\text { - as diagonais } \overline{A B} \text { e } \overline{D E} \text { são } \\
\text { obliquas; } \\
\text { - as diagonais são diâmetros da } \\
\text { circunferência d, portanto } \overline{A B}=\overline{D E} \\
\text { - as diagonais se interceptam no } \\
\text { ponto médio C } \\
\text { - } \triangle A C D \equiv \triangle E C B \text { pois } \overline{A C} \equiv \overline{E C}, \\
\angle \mathrm{ACD}=\angle \mathrm{ECB} \text { e } \overline{C D} \equiv \overline{C B}, \text { portanto } \\
\overline{A D} \equiv \overline{E B} \\
-\triangle A D B \equiv \triangle E B D \text { pois } \overline{A D} \equiv \overline{E B}, \\
<\mathrm{ADB}=\angle \mathrm{EBD}=90^{\circ}, \overline{D B} \text { é lado } \\
\text { dos dois triângulos, portanto } \overline{A B}= \\
\overline{D E} \\
-\triangle A D B \equiv \triangle B E A \text { pois } \overline{A D}=\overline{B E}, \\
\angle \mathrm{ADB}=\angle \mathrm{BEA}=90^{\circ}, \overline{A B} \text { é lado } \\
\text { dos dois triângulos, portanto } \overline{D B} \equiv \\
\overline{A E} \\
-\angle \mathrm{ADB}=\angle \mathrm{DBE}=\angle \mathrm{BEA}=\angle \mathrm{EAD}= \\
90^{\circ} \\
-\overline{A E} \| \overline{D B} \text { e } \overline{A D} \| \overline{E B}\end{array}$ \\
\hline
\end{tabular}

Figura 7 - Fatos declarados e implícitos

Fonte: http://www.ufrgs.br/espmat

O exame do arquivo do GeoGebra também permite constatar que as regularidades e as propriedades geométricas ficam evidenciadas do ponto de vista do dinamismo do GeoGebra e que, do ponto de vista dos conceitos matemáticos, A identifica com clareza as propriedades das diagonais também na construção do losango e do paralelogramo.

\section{Gênese Profissional}

A análise da gênese profissional apoiou-se sobre a tarefa de elaboração de um plano de aula, proposta pela disciplina TP-I, com o objetivo de pensar a sala de aula a partir dos conteúdos e recursos digitais trabalhados em MD-I, e sobre os resultados evidenciados na prática realizada para a elaboração do TCC.

Para a elaboração do plano de aula, os professores consideraram as seguintes orientações gerais: 1) o tema abordado deve envolver os tópicos estudados na disciplina, ou apresentar relação direta com estes conteúdos (geometria e figuras, geometria e álgebra, geometria e funções); 2) apresente uma justificativa para a escolha do tema abordado; 3) o plano de aula é destinado para apenas uma aula; 4) o plano deve envolver a utilização do GeoGebra, explorando o potencial de utilização deste recurso para promoção de aprendizagem matemática; 5) apresente uma sequência de atividades ou questões a serem apresentadas aos alunos para realização do plano; 6) descreva o papel do professor durante a 
DOl: http://dx.doi.org/10.20396/zet.v25i2.8647864

realização desta aula. Que tipo de intervenções são feitas? Como conduz a atividade? Como questiona os alunos? Que tipo de postura deve adotar em cada situação não prevista, tal como perguntas inusitadas, etc.?

A atividade de elaboração do plano de aula ocorreu em dois momentos: em um primeiro, os professores elaboraram um plano de aula individual e, em um segundo momento, os professores foram convidados a se reunirem em grupos de três alunos com a tarefa de escolher um dos planos de algum integrante do grupo para aperfeiçoar dos pontos de vista didático, matemático e de uso de tecnologias em sala de aula, ou desenvolver e aperfeiçoar um plano de aula com origem em mais de um plano dos integrantes do grupo. Vamos analisar o plano de aula elaborado de forma individual.

O plano de aula individual apresentado por A teve como proposta trabalhar com o quadrilátero retângulo, contemplando o tópico geometria e figuras. Dentre os objetivos do plano de A, podemos apontar alguns: reconhecer um retângulo como um paralelogramo de ângulos congruentes, reconhecer e representar as diagonais de um retângulo, demonstrar as propriedades das diagonais do retângulo.

É interessante observar que A retoma no seu plano de aula a tarefa III, tratando da construção de quadrilátero a partir das diagonais. O professor A inicia propondo construção de retângulo a partir de pontos com coordenadas, propõe a construção das diagonais do retângulo, solicita o uso de medidas e faz uso da exploração de movimento para mostrar que o quadrilátero perde as características, por não ter sido construído a partir das propriedades que o definem. Na sequência, A propõe uma atividade de construção de retângulo estável, mas particular, conforme o retângulo construído na tarefa III.

Do ponto de vista da tomada de consciência do potencial do dinamismo do GeoGebra, percebe-se que A reconhece a importância das figuras dinâmicas na aprendizagem de propriedades geométricas, pois tira proveito da representação dinâmica, iniciando com uma construção que não é estável para provocar a ideia de estabilidade das figuras dinâmicas. Assim, percebe-se que A está em um processo de descoberta das funcionalidades didáticas do GeoGebra, propondo sua utilização como uma estratégia de ensino de forma pertinente e revelando indícios de um processo de gênese profissional (Haspekian, 2013).

No plano elaborado, observam-se provocações para o aluno no sentido de movimentar vértices e ver o que acontece com o retângulo, ou de fazer uma construção que seja estável ao ser movimentada. O professor A está revelando a utilização de esquemas de gestão de classe e a preocupação com a aprendizagem dos alunos a partir do uso do GeoGebra, usando o potencial didático do instrumento. $\mathrm{O}$ assunto está bem encaminhado, incorporando importantes aspectos da formação recebida, como por exemplo, no desafio proposto por A: "Há outra maneira de construir um retângulo no GeoGebra, que mantenha suas propriedades ao movimentar os vértices? Qual?". Percebe-se que A está em processo de construção de um instrumento didático, a partir do instrumento que está sendo construído pela gênese pessoal. 
DOl: http://dx.doi.org/10.20396/zet.v25i2.8647864

O software GeoGebra ainda está se tornando um instrumento pessoal para A. Este professor, sem conhecimento sobre o uso do GeoGebra até o início do Curso, está explorando e desvendando o instrumento na dimensão pessoal e, portanto, este ainda não se constitui totalmente em um instrumento didático para ensinar Matemática, mas vai, progressivamente, se transformando pelo processo de gênese profissional. Vale ressaltar que, ao analisar planos de ensino de outros cursistas, não foi possível identificar a tomada de consciência sobre o potencial do GeoGebra para uso em sala de aula.

Outra evidência de indícios do processo de gênese profissional de A pode ser identificada a partir da construção e implementação de prática destinada para 28 estudantes do $2^{\circ}$ Ano do Ensino Médio Politécnico de escola pública localizada no Rio Grande do Sul.

O professor A propôs uma experiência didática para o ensino da função seno fazendo referência a fenômenos periódicos utilizando um objeto digital de aprendizagem que simula ondas, o software GeoGebra e um vídeo sobre ondas.

A escolha do GeoGebra, segundo A, deveu-se ao fato de ser "uma interessante ferramenta de geometria dinâmica, ao contrário do que é apresentado em livros didáticos de maneira estática e que dificulta o aprendizado”. Temos aqui indícios de que A já reconhece o GeoGebra como um instrumento para a aprendizagem de Matemática, neste caso apontando o potencial do dinamismo que o instrumento proporciona. O professor A também refere que "Ao representar o gráfico da função seno no GeoGebra, tem-se na janela de álgebra a expressão algébrica da função. $O$ dinamismo deste programa caracteriza-se pela manipulação direta sobre o gráfico, por exemplo, sendo que as alterações no gráfico imediatamente são visíveis na janela de álgebra. Este dinamismo é o que permite ao professor e aluno o "fazer matemática" (...)”. Percebemos que A destaca a versatilidade do instrumento em proporcionar as manipulações algébrica e gráfica de forma simultânea e realça que este potencial é o que permite ao aluno o "fazer matemática", ou seja, A está em processo de gênese profissional do GeoGebra, provavelmente sendo construído simultaneamente com o processo de gênese pessoal, a partir das atividades do Curso. Como afirma Haspekian (2013), a gênese profissional se dá pela elaboração do instrumento didático a partir do instrumento construído pela gênese pessoal e que ambas as dimensões da gênese instrumental podem se desenvolver juntas.

Ao utilizar o GeoGebra, A propõem duas construções a serem feitas e exploradas pelos estudantes. Na primeira, propõe a construção do círculo trigonométrico simultaneamente à construção da função seno, associadas a perguntas sobre o comportamento do gráfico que conduzissem os estudantes a compreenderem os conceitos envolvidos. $\mathrm{Na}$ segunda, propõe a construção de $f(x)=a+b \times \operatorname{sen}(c x+d)$, utilizando o recurso de controles deslizantes. Assim como na primeira construção, também aqui A leva seus alunos a construírem os conceitos matemáticos a partir de questões formuladas com base na exploração da construção feita no GeoGebra. Percebemos, pela análise do trabalho de A, que não se trata apenas de exercícios de construção de gráficos, mas de atividades que provocam os alunos a refletirem sobre os conceitos matemáticos em jogo a partir do uso do GeoGebra, 
DOI: http://dx.doi.org/10.20396/zet.v25i2.8647864

ressaltando que A está tomando consciência do potencial deste instrumento para uso em sala de aula.

Podemos dizer que A está em processo de gênese instrumental pessoal para o uso do GeoGebra. Nas duas situações analisadas, identificamos indícios do processo de gênese instrumental profissional. Em ambos, A faz considerações didáticas pertinentes sobre o uso da geometria dinâmica, evidenciando um processo de gênese profissional em amadurecimento. Sua proposta de ensino e sua prática para elaboração do TCC são modestas, mas apresentam um caráter exploratório que faz uso do dinamismo do software.

\section{Considerações Finais}

Neste artigo, analisamos o processo de gênese instrumental, nos níveis pessoal e profissional, por meio de um estudo de caso de um dos professores matriculados no Curso de Especialização em Matemática - Mídias Digitais - Didática.

O que esse estudo nos revelou?

A análise desse caso particular, a partir de construções realizadas no GeoGebra pelo sujeito investigado, revelou uma progressiva transformação do artefato em instrumento (Rabardel, 1995). O sujeito A, frente a um conjunto de atividades específicas envolvendo o uso do GeoGebra, reconhecendo potencialidades do software, desenvolveu esquemas de utilização que lhe permitiram resolver as situações propostas e, de maneira recíproca, essas resoluções implicaram no desenvolvimento de novos esquemas de utilização. A análise desse processo recíproco, longo e complexo, como destacado por Rabardel (1995), oferece a possibilidade de identificarmos uma gênese instrumental do sujeito A.

Um aspecto relevante desse estudo, é o fato do sujeito A desconhecer o uso do software GeoGebra ao iniciar seus estudos no Curso e que, no período de tempo dessa formação, foi possível identificar evidências quanto à apropriação desse recurso digital e indícios de sua utilização no espaço profissional.

Embora o caso seja particularístico, ele oferece elementos que nos permitem refletir não apenas sobre o processo individual do sujeito A, mas também sobre a proposta pedagógica do Curso. Como? No caso em estudo, os dados e análises sugerem o desenvolvimento de esquemas de utilização pessoal e profissional do sujeito A, o que vem ao encontro da proposta pedagógica do Curso e, em particular, sugerem a adequação das atividades presentes no par de disciplinas Mídias Digitais I e Prática Pedagógica I, no sentido de contribuir para a gênese instrumental de A.

Mas há que se destacar que, ao mesmo tempo em que a abordagem instrumental de Rabardel está sendo utilizada para analisar os dados, ela oferece a sustentação para estruturar o desenho do Curso no seu largo conjunto de atividades. Mais especificamente, a abordagem de Rabardel se manifesta no trabalho integrado das disciplinas aos pares e, especificamente nesse artigo, na integração das disciplinas Mídias Digitais I e Prática Pedagógica I. 
DOI: http://dx.doi.org/10.20396/zet.v25i2.8647864

Assim, a imbricação entre a teoria e a proposta didática se mostrou potencialmente adequada no contexto da apropriação dos recursos do GeoGebra e de seu uso na Escola no presente estudo de caso.

$\mathrm{Na}$ pesquisa, cujo recorte foi apresentado nesse artigo, a análise do processo de gênese instrumental está sendo realizada tomando um conjunto ampliado de dados de professores. Análises similares estão sendo feitas para os demais pares de disciplinas do curso, nas quais foram utilizados outros recursos digitais, como os softwares Winplot e GrafEq.

As análises preliminares desse conjunto ampliado de produções dos professores, utilizando a abordagem instrumental de Rabardel, apontam no sentido que as atividades propostas nas disciplinas do Curso, especificamente no que se refere à apropriação do GeoGebra e que desencadeiam o processo de gênese pessoal, têm produzido reflexos similares aos apresentados neste artigo em relação à gênese profissional. Particularmente, as práticas implementadas em sala de aula, parte integrante dos trabalhos de conclusão de Curso até aqui analisados, sugerem que recursos digitais, dentre eles destacadamente o GeoGebra, têm sido incorporados de modo a tirar proveito do potencial que podem proporcionar na aprendizagem de matemática escolar.

Ainda que os dados apontem para a adequação das escolhas teórica e didática da proposta do Curso de Especialização Matemática - Mídias Digitais - Didática, a pesquisa prossegue na direção da construção e validação de um modelo de curso a distância que favoreça o desenvolvimento das gêneses instrumentais pessoal e profissional.

\section{Agradecimentos}

Agradecemos o apoio da FAPERGS, dentro do Programa de Internacionalização da Pós-Graduação no RS e à parceria com os colegas do Projeto Tecnologia Digital na Formação de Professores de Matemática da Educação Básica, desenvolvido entre o PPGEMAT/UFRGS e o LDAR/Université Denis Diderot - Paris 7. Finalmente, agradecemos à CAPES/UAB pelo apoio na realização do Curso de Especialização Matemática - Mídias Digitais - Didática: Tripé para Formação do Professor de Matemática.

\section{Referências}

Abboud-Blanchard, M., Vandebrouck, F. (2013). De l'anlyse d'usages des TICE à unbe articulation de cadres théoriques pour l'étude des pratiques enseignantes. In: Les technologies numériques pour lénseignement. Toulouse: OCTARÈS Editions.

Artigue, M. (2002). Learning mathematics in a CAS environment: the genesis of a reflection about instrumentation and dialectics between technical and conceptual work. International Journal of Computers for Mathematical Learning, Netherlands, (7), 245274. 
DOI: http://dx.doi.org/10.20396/zet.v25i2.8647864

Bittar, M. A. (2011). A abordagem instrumental para o estudo da integração da tecnologia na prática pedagógica do professor de matemática. Educar em Revista, Curitiba, 27 (1), 157-171.

Bueno-Ravel, L., \& Guedet, G. (2013). L'approche instrumentale des genèses d'usage: le cas des bases d'exercices en ligne. In: Les technologies numériques pour lénseignement. Toulouse: OCTARÈS Editions.

Haspekian, M. (2013). Enseigner avec un tableur: quelles genèses instrumentales? In: Les technologies numériques pour lénseignement: usages, dispositifs et genèses. Toulouse: OCTARÈS Editions.

Lagrange, J.B. (2013). Les technologies numériques pour lénseignement: usages, dispositifs et genèses. Toulouse: OCTARÈS Editions.

Ponte, J. P. (2006). Estudos de Caso em Educação Matemática. Bolema, Rio Claro, 19 (25), 105-132.

Rabardel, P. (1995). Les hommes et les technologies: une approche cognitive des instruments contemporains. Paris: Armand Colin.

Trouche, L. (2004). Managing the complexity os human/machine interactions in computerized learning environment: guiding student's command process through instrumental orchestrations. International Journal of Computers for Mathematical Learning, Netherlands, (9), 281-307. 